\title{
Analisis Model Random Intersep 3-Level Pada Regresi Linear Multilevel Untuk Data Pengukuran Berulang
}

\author{
Arie Purwanto \\ Program Studi Pendidikan Matematika, Fakultas Keguruan dan IImu Pendidikan, \\ Universitas Mercu Buana Yogyakarta \\ Email : arie@mercubuana-yogya.ac.id
}

(Naskah masuk: 9 Juli 2019, diterima untuk diterbitkan: 23 Juli 2019)

\begin{abstract}
ABSTRAK
Tujuan dari penelitian ini antara lain sebagai pengembangan dalam analisis data yakni regresi linier untuk data bertingkat (multilevel). Struktur data pengukuran berulang dimana setiap pengukuran atau observasi yang dilakukan secara berulang dilakukan untuk individu yang sama secara langsung merupakan salah satu jenis data multilevel. Dalam hal ini, analisis data yang ditemukan dengan menggunakan analisis regresi linier multilevel untuk tiga level. Metode yang digunakan adalah Maximum Likelihood Estimation (MLE) dengan menggunakan Iterative Generalized Least Square (IGLS). Data yang digunakan adalah data nilai pre-test, tugas, dan post-test, dimana setiap nilai diamati sebanyak tiga kali untuk setiap individu yang tersebar pada 5 kelas yang berbeda. Model random intersep digunakan dalam analisis regresi multilevel untuk data pengukuran berulang dengan model 3-level. Hasil yang diperoleh menunjukkan bahwa untuk setiap kenaikan level ditemukan bahwa nilai AIC dan BIC cenderung menurun yang dapat diartikan bahwa model yang digunakan semakin baik. Selain itu, ditemukan pula bahwa interclass correlation (ICC) pada level 2 yakni sebesar 0,0497 sedangkan pada level-3 sebesar 0,0897 yang menunjukkan bahwa variabelitas di tingkat kelas lebih tinggi yakni $8,97 \%$.
\end{abstract}

Kata kunci : multilevel, pengukuran berulang

\begin{abstract}
The purpose of this study IS as a development in data analysis namely linear regression for multilevel data. The structure of repeated measurement data where each measurement or observation have repeatedly for the same individual directly is one of multilevel data type. In this case, data analysis is found by using multilevel linear regression analysis for three levels. The method used is Maximum Likelihood Estimation (MLE) using Iterative Generalized Least Square (IGLS). The data that used in this reaserach are pre-test, assignment, and post-test scores, where each value is observed three times for each individual that distributed over five different classes. The random intercept model is used in multilevel regression analysis for repeated measurement data with a 3-level model. The results obtained indicate that for each level increase it is found that the value of AIC and BIC tends to decrease which means that the model used is getting better. In addition, it was also found that the interclass correlation (ICC) at level 2 was equal to 0.0493 while at level-3 amounted to 0.0897 which showed that the variability at the grade level was higher at $8.97 \%$.
\end{abstract}

Keywords: multilevel, repeat measurement

\section{PENDAHULUAN}

Analisis regresi linier merupakan salah satu metode analisis statistika yang sangat popoler untuk melihat hubungan antara variabel respon dengan satu atau lebih variabel prediktor. Seiring dengan perkembangan jaman, kebutuhan akan analisis data yang sangat kompleks turut 
dikembangkan guna memperoleh hasil analisis yang jauh lebih baik. Kosep dasar dalam analisis regresi multilevel lahir ketika variabel-variabel

pengamatan

dikelompokan dalam unit-unit dimana variabel tersebut diamati. Hasil pengelompokan (klusterisasi) pengamatan dalam unit ini yang selanjutnya memunculkan adanya tingkatan, hirarki, atau level dalam struktur data. Struktur data pengukuran berulang dalam konteks regresi multilevel diartikan sebagai pengamatan variabel-variabel yang bersarang pada individu (subyek pengamatan) secara berulang, dalam hal ini dapat ditemukan adanya unit-unit pengamatan yang bersarang pada individu yang bersesuaian sehingga dapat dibentuk adanya tingkatan atau level dalam variabel pengamatan. nilai pre-test, tugas, dan posttest masing-masing sebanyak 3 kali pada mata kuliah aljabar linier selama 1 semester. Metode estimasi parameter yang digunakan adalah metode maksimum likelihood, Menurut Rencher, et.al (2008) estimator maksimum likelihood (MLE) memiliki hasil yang sama dengan metode Ordinary Least Square (OLS). Metode OLS secara umum untuk dikembangkan atau digeneralisasikan dengan sebutan Generalized Least Square (GLS). Metode ini yang kemudian dikembangkan sebagai prosedur iterasi dan lebih dikenal dengan nama metode Iterative Generalized Least Square (IGLS) dan diterapkan untuk memperoleh hasil estimasi parameter disetiap level-nya. Lebih lanjut, ditentukan ilai Interclass Correlation (ICC) untuk mengetahui hubungan antar level dari hasil estimasi yang dilakukan dan pengukuran AIC dan BIC untuk mengetahui sebagai ukuran kebaikan model.

Dalam penelitian ini model yang digunakan adalah model regresi linier multilevel untuk data pengukuran berulang. Penetapan level dapat dilakukan dengan mendefinisikan pengukuran atau pengamatan berulang sebagai level-1, individu dimana pengukuran berulang tersebut dilakukan adalah level-2, dan lokasi individu tersebut diamati adalah level-3. Dalam penelitian ini pengukuran berulang dilakukan sebanyak 3 kali untuk setiap mahasiswa sebagai subyek penelitian. Pengukuran yang dimaksud adalah pengukuran nilai-nilai pre-test, tugas, dan post-test masingmasing sebanyak 3 kali pada mata kuliah aljabar linier selama 1 semester. Metode estimasi parameter yang digunakan adalah metode maksimum likelihood, Menurut Rencher, et.al (2008) estimator maksimum likelihood (MLE) memiliki hasil yang sama dengan metode Ordinary Least Square (OLS). Metode OLS secara umum untuk dikembangkan atau digeneralisasikan dengan sebutan Generalized Least Square (GLS). Metode ini yang kemudian dikembangkan sebagai prosedur iterasi dan lebih dikenal dengan nama metode Iterative Generalized Least Square (IGLS) dan diterapkan untuk memperoleh hasil estimasi parameter disetiap level-nya. Lebih lanjut, ditentukan ilai Interclass Correlation (ICC) untuk mengetahui hubungan antar level dari hasil estimasi yang dilakukan dan pengukuran AIC dan BIC untuk mengetahui sebagai ukuran kebaikan model.

\section{ANALISIS DATA}




\subsection{Model random intersep pada Regresi Linier Multilevel untuk Data Pengukuran Berulang}

Variabel respon $y_{i j k}$ untuk $(i=1,2, \ldots, l ; j=1,2, \ldots, n ; k=1,2, \ldots, m)$

merepresentasikan pengukuran ke-i pada level-1 yang bersarang pada individu ke-j pada level-2 dan berlokasi di- $k$ pada level3. Prediktor $x_{h i j k}$ untuk $(h=1,2, \ldots, p)$ dapat diartikan untuk prediktor ke- $h$ untuk pengukuran pengukuran ke-i pada level-1 yang bersarang pada individu ke-j pada level-2 dan berlokasi di- $k$ pada level-3. Banyaknya pengukuran berulang yang dilakukan pada individu ke-j dinotasikan dengan $n_{i j}$, sedangkan $n$ menyatakan total observasi yang telah dilakukan. Total pengamatan dirumuskan sebagai berikut:

$n=\sum_{j=1}^{n} \sum_{i=1}^{l} n_{i j}$

Stuktur data multilevel untuk data pengukuran berulang merupakan struktur data yang unik. Hal ini terjadi dikarenakan dalam struktur data pengukuran berulang pengukuran atau pengamatan dilakukan beberapa kali untuk individu yang sama. ntuk individu ke- $j$ yang yang berada pada lokasi ke-k

$e_{i j k}$ adalah efek random untuk pengukuran ke- $i$ yang bersarang pada individu ke-j dan berada pada lokasi ke- $k$ dengan $e_{i j k}$ diasumsikan berditribusi $N\left(0, \sigma_{e 0}^{2}\right)$

Model persamaan 2 level dibentuk berdasarkan model persamaan-persamaan (2.2). Model dapat diperoleh dengan mendefinisikan variabel random baru yang merepresentasikan kondisi persamaan pada level-2 secara keseluruhan. Kondisi pada level-2 mengharuskan terbentuknya sebuah persamaan regresi yang merepresentasikan data secara menyeluruh. Salah satu yang dapat model regresi yang dapat dilakukan dengan mendefinisikan model intersep multilevel.
Hasil analisis data yang dilakukan dengan mengambil subyek yang sama sehinga dimungkinkan memiliki variabilitas yang relatif rendah. Dalam analisis regresi linier multilevel, pemahaman tentang gambaran struktur data dalam proses analisis sangat penting guna melakukan estimasi parameter yang diinginkan. Misalkan diberikan persamaan regresi linier sebagai berikut:

$y_{i j k}=\beta_{0 j k}+\sum_{h=1}^{p} \beta_{h j k} x_{h i j k}+e_{i j k}$ dengan:

$y_{i j k}$ adalah variabel respon untuk pengukuran ke- $i$ yang bersarang pada individu ke-j dan berada pada lokasi ke- $k$

$x_{\text {hijk }}$ adalah variabel prediktor ke- $h$ untuk pengukuran ke- $i$ untuk bersarang pada individu ke-j dan berada pada lokasi ke- $k$

$\beta_{0 j k}$ adalah random intersep untuk individu ke- $j$ yang yang berada pada lokasi ke-k

$\beta_{h j k}$ adalah random slope variabel prediktor ke- $h$, u Model random intersep pada level-2 disajikan sebagai berikut:

$\beta_{0 j k}=\beta_{00 k}+u_{0 j k}$

dengan:

$\beta_{0 k} \quad$ adalah intersep untuk setiap lokasi

$u_{0 j k}$ adalah efek random yang berasal

dari $\beta_{00 k}$ untuk setiap individu ke-j

yang berada pada lokasi ke- $k$ dengan

$u_{0 j k}$ diasumsikan berditribusi $N\left(0, \sigma_{u}^{2}\right)$

Persamaan (2.3) secara sederhana dapat diilustrasikan sebagai suatu intersep untuk masing-masing individu yang mengandung intersep secara keseluhan beserta efek random untuk setiap individu. Efek random ini merepresentasikan jarak antara intersep masing-masing individu terhadap intersep keseluruhan. Persamaan (2.3) jika disubtitusikan ke dalam persamaan (2.2) akan menghasilkan model penuh persamaan untuk regresi multilevel 
pengukuran berulang 2 level sebagai berikut:

$$
\begin{aligned}
y_{i j k}= & \beta_{00 k}+u_{0 j k}+\sum_{h=1}^{p} \beta_{h j k} x_{h i j k}+e_{i j k} \\
= & \beta_{00 k}+\sum_{h=1}^{p} \beta_{h j k} x_{h i j k} \\
& +u_{0 j k}+e_{i j k} \\
& \text { Untuk model persamaan 3-level }
\end{aligned}
$$
dibentuk berdasarkan model persamaanpersamaan pada level-2. Model dapat diperoleh dengan mendefinisikan variabel random baru yang merepresentasikan kondisi persamaan pada level-3 secara keseluruhan. Kondisi pada level-3 mengharuskan terbentuknya sebuah persamaan regresi yang merepresentasikan data secara menyeluruh. Salah satu yang dapat model regresi yang dapat dilakukan dengan mendefinisikan model intersep multilevel. Model intersep yang dimaksud dalam kasus ini adalah sebagai berikut:

dengan:

$$
\beta_{00 k}=\beta_{000}+v_{00 k}
$$

$v_{00 k} \quad$ adalah efek random yang berasal dari $\beta_{00 k}$ untuk lokasi ke- $k$ dengan $v_{00 k}$ diasumsikanberditribusi $N\left(0, \sigma_{v}^{2}\right)$

Persamaan (2.5) jika disubtitusikan ke dalam persamaan (2.4) akan menghasilkan model penuh persamaan regresi multilevel pengukuran berulang 3level sebagai berikut:

$$
\begin{aligned}
y_{i j k}= & \beta_{000}+\sum_{h=1}^{p} \beta_{h j k} x_{h i j k}+v_{00 k} \\
& +u_{0 j k}+e_{i j k}
\end{aligned}
$$

Persamaan (2.6) inilah yang kemudian disebut dengan model random intersep intersep 3-level. Model ini menjadi dasar bagi pemodelan regresi lain yang dengan menitikberatkan struktur linier dalam modelnya. Selain itu, model random intersep ini dapat diperluas sesuai dengan struktur data. Konsep dasar yang melandasi pembentukan dan perluasan model secara umum adalah logika dalam pemodelan. Pengamatan mendalam untuk data yang digunakan sangat diperlukan agar sesuai dengan model yang digunakan. Model (2.6) membutuhkan beberapa asumsi yang harus dipenuhi. Asumsi yang dimaksud adalah sebagai berikut:

$$
\begin{aligned}
& E\left(\beta_{0 j k}\right)=\beta_{00 k} \quad \operatorname{var}\left(e_{i h}\right)=\sigma_{e}^{2} \\
& E\left(\beta_{00 k}\right)=\beta_{000} \quad \operatorname{var}\left(\beta_{0 j k}\right)=\sigma_{u}^{2} \\
& E\left(\beta_{h j k}\right)=\beta_{h} \quad \operatorname{var}\left(\beta_{00 k}\right)=\sigma_{v}^{2} .
\end{aligned}
$$

Untuk kepentingan estimasi lebih lanjut model persamaan (2.6) dapat diperluas dan disesuaikan dengan berdasarkan monograf Brian Cullis dan Alison Smith yakni:

$\mathrm{Y}=\mathrm{X} \beta+\mathrm{Z}_{1} \mathrm{v}+\mathrm{Z}_{2} \mathrm{u}+\mathrm{e}$

dengan:

$\mathrm{Z}_{1}$ merupakan matrik penjelas berukuran $n \times n$

$\mathrm{Z}_{2}$ merupakan matrik penjelas berukuran $n \times n$

$\mathrm{v}$ adalah vektor berukuran $n \times 1$ berisi efek random dari level-3

$\mathrm{u}$ adalah vektor berukuran $n \times 1$ berisi efek random dari level-2

e adalah vektor berukuran $n \times 1$ berisi efek random dari level-1

\subsection{Prosedur Estimasi}

Dalam prosedur estimasi parameter untuk persamaan (2.6) dapat dituliskan sebagai berikut:

$$
\begin{aligned}
y_{i j k}^{*(t)}= & x_{h i j k} \beta^{(t)}+v_{00 k}{ }^{(t)} \\
& +u_{0 j k}{ }^{(t)}+e_{i j k}^{*(t)}
\end{aligned}
$$

Prosedur iterasi IGLS secara umum sama dengan metode estimasi GLS. Langkah pertama adalah menaksir parameter $\beta$. Diperhatikan bahwa dalam persamaan (2.8) estimator untuk $\beta$ yakni $\widehat{\beta}$ dapat cari dengan cara sebagai berikut:

$\widehat{\beta}^{(t)}=\left(\mathrm{X}^{\prime} \mathrm{V}^{-1} \mathrm{X}\right)^{-1} \mathrm{X}^{\prime} \mathrm{V}^{-1} y^{*}$

dengan

$\mathrm{V}=\mathrm{Z}_{1} \mathrm{~V}_{1} \mathrm{Z}_{1}{ }^{T}+\mathrm{V}_{2}$ untuk level-2

dan

$\mathrm{V}=\mathrm{Z}_{3} \mathrm{~V}_{3} \mathrm{Z}_{3}{ }^{T}+\mathrm{Z}_{2} \mathrm{~V}_{2} \mathrm{Z}_{2}{ }^{T}+\mathrm{V}_{3}$ untuk level-3 
Proses iterasi yang dilakukan memerlukan nilai tebakan awal untuk melakukan estimasi terhadap $\beta$, maka menurut prosedur IGLS dapat digunakan nilai tebakan awal untuk parameter $\beta$ sebagai berikut:

$\hat{\beta}^{(0)}=\left(X^{T} X\right)^{-1} X^{T} y$

Pendekatan untuk $\hat{\beta}$ pada persamaan (2.9) memuat nilai $\mathrm{V}$ yang tidak diketahui. Nilai $\mathrm{V}$ dapat dicari dengan diperoleh dengan cara sebagai berikut:

Misalkan:

$$
\tilde{y}^{*}=\mathrm{y}^{*}-\hat{\mathrm{y}}^{*}=\mathrm{y}^{*}-\mathrm{X} \widehat{\beta}^{(t)}
$$

menurut penurunan (2.11) diperoleh nilai $E\left(\tilde{y}^{*} \tilde{y}^{* T}\right)$ sebagai berikut:

$E\left(\tilde{y}^{*} \tilde{y}^{* T}\right)=\mathrm{V}$

vektorisasi (2.12) diperoleh sebagai berikut:

$\mathrm{y}^{* *}=\operatorname{vec}\left(\tilde{y}^{*} \tilde{y}^{* T}\right)$

misalkan:

$E\left(\mathrm{y}^{* *}\right)=\mathrm{Z}^{*} \theta$

$\operatorname{cov}\left(\mathrm{y}^{* *}\right)=\mathrm{V}^{*}$

Dengan $\mathrm{Z}^{*}$ merupakan matrik yang didesain untuk parameter variansi $\theta$ maka berdasarkan GLS dapat dibentuk estimasi parameter $\theta$ sebagai berikut:

$\hat{\theta}^{(t)}=\left(\mathrm{Z}^{* T} \mathrm{~V}^{*^{-1}} \mathrm{Z}^{*}\right)^{-1} \mathrm{Z}^{* T} \mathrm{~V}^{*^{-1}} \mathrm{y}^{* *}$

dengan:

$\theta=\left[\begin{array}{l}\hat{\sigma}_{v}^{2} \\ \hat{\sigma}_{u}^{2} \\ \hat{\sigma}_{e}^{2}\end{array}\right]$

$\mathrm{V}^{*}=\mathrm{V} \otimes \mathrm{V}$

\section{SIMULASI}

\subsection{Deskripsi Variabel}

Variabel yang digunakan dalam simulasi data adalah nilai pre-test, tugas dan post-test. Sebanyak 202 mahasiswa diambil sebagai sampel dimana mahasiswa tersebut tersebar dalam 5 kelas yang berbeda. Setiap mahasiswa diukur sebanyak 3 kali pengukuran yakni pengukuran nilai pre-test, tugas, dan posttest. Sehingga terdapat sebanyak 606 unit pengukuran yang bersarang pada sebanyak 202 mahasiswa dimana 202 mahasiswa tersebut tersebar dalam 5 kelas yang berbeda Pre-test dapat diartikan sebagai kegiatan pengujian pengetahuan siswa terhadap materi yang akan disampaikan. pemberian tugas bermaksud agar siswa terampil menyelesaikan soal, teori memahami, dan mendalami pelajaran yang diberikan di sekolah. Post-test dapat diartikan sebagai bentuk pertanyaan yang diberikan setelah pelajaran ataupun tes evalausi akhir saat materi yang di ajarkan, sehingga post-test dapat dijadikan variabel respon.

\section{Hasil dan Pembahasan}

\subsection{Analisis model pada level-1}

Pada level-1 atau dapat diartikan sebagai level pengukuran terdapat sebanyak 606 obeservasi yang dilakuakan dan bersarang pada sebanyak 202 mahasiswa. Dalam bahasa standar model statistik multilevel persamaan model 1 level dapat dibentuk model sebagai berikut:

$y_{i j k}=\beta_{0 i j}+\beta_{1 i j} x_{i j k}+\beta_{2 i j} x_{i j k}+e_{i j k}$

dengan:

$e_{i j k} \sim N\left(0, \sigma_{e}^{2}\right)$

Hasil analisis yang dilakukan pada level-1 disajikan dalam Tabel 1. sebagai berikut:

Tabel 1. Hasil Analisis pada Level-1

\begin{tabular}{lcccc}
\hline Parameter & $\begin{array}{c}\text { Estimasi } \\
\text { parameter }\end{array}$ & $\begin{array}{c}\text { p- } \\
\text { value }\end{array}$ & AIC & BIC \\
\hline Cons & 32.15 & 0.00 & & \\
Pre-test & 0.20 & 0.00 & 3799 & 3812. \\
Tugas & 0.45 & 0.00 & & 52
\end{tabular}




$$
\begin{aligned}
& \left.\begin{array}{lll}
\mathrm{Sd} \\
\left(\sigma_{e}\right)
\end{array}\right) \text { level-1 } \quad 5.53 \quad 0.00
\end{aligned}
$$

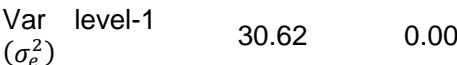

$$
\begin{aligned}
& \text { Dalam model 1-level bentuk } \\
& \text { persamaan dapat dituliskan sebagai } \\
& E\left[y_{i j k}\right]=E\left[\beta_{0 i j}+\beta_{1 i j} x_{1 i j k}+\beta_{2 i j} x_{2 i j k}+e_{i j k}\right] \\
& \hat{y}_{i j k}=\beta_{0 i j}+\beta_{1 i j} x_{1 i j k}+\beta_{2 i j} x_{2 i j k}
\end{aligned}
$$

Subtitusi persamaan hasil estimasi parameter pada Tabel 4.1 dalam persamaan (4.3) diperoleh hasil sebagai berikut:

$\hat{y}_{i j k}=32.15+0.20 x_{1 i j k}+0.45 x_{2 i j k}$

\subsection{Analisis Model Pada Level-2}

Sejalan dengan analisis pada level- 1 , pada level-2 terdapat sebanayak 202 persamaan regresi yang tersarang dalam 5 kelas. Persamaan model untuk level 2 dapat dibangun dengan cara sebagai berikut:

Missal diverikan persamaan pada level-2 sebagai berikut:

$\beta_{0 i j}=\beta_{0 i}+u_{0 i j}$

dengan

$u_{0 i j} \sim N\left(0, \sigma_{u}^{2}\right)$

dimana:

$E\left(\beta_{0 i j}\right)=\beta_{00 i}$ dan $\operatorname{var}\left(\beta_{0 i j}\right)=\sigma_{u}^{2}$

Subtitusi persamaan (4.5) dalam persamaan (4.1) diperoleh model penuh untuk 2 level dapat dituliskan sebagai berikut:

$$
\begin{aligned}
y_{i j k}= & \beta_{00 i}+\beta_{1 i j} x_{i j k}+\beta_{2 i j} x_{i j k} \\
& +e_{i j k}+u_{0 i j}
\end{aligned}
$$

Dari hasil analisis untuk model pada level-2 dijabarkan pada Tabel 2. sebagai berikut:

\section{Tabel 2. Hasil Analisis pada Level-2}

\begin{tabular}{lcccc}
\hline $\begin{array}{c}\text { Paramete } \\
\mathbf{r}\end{array}$ & $\begin{array}{c}\text { Estimasi } \\
\text { paramete } \\
\mathbf{r}\end{array}$ & $\begin{array}{c}\mathbf{p}- \\
\text { valu } \\
\mathbf{e}\end{array}$ & AIC & BIC \\
\hline Cons & 30.65 & 0.00 & 3780.2 & 3802.2 \\
\cline { 3 - 5 }
\end{tabular}

\begin{tabular}{lllll} 
Pre-test & 0.20 & 0.00 & 3 & 6 \\
Tugas & 0.46 & 0.00 & & \\
$\begin{array}{l}\text { Sd level-1 } \\
\left(\sigma_{e}\right)\end{array}$ & 5.40 & 0.00 & \\
$\begin{array}{l}\text { Sd level-2 } \\
\left(\sigma_{u}\right)\end{array}$ & 1.23 & 0.01 & \\
\hline
\end{tabular}

Dalam model bentuk persamaan pada level-2 dapat dituliskan sebagai berikut:

Diperhatikan persamaan ,dengan mempertimbangkan persamaan (4.2) dan (4.6) maka diperoleh persamaan sebagai berikut:

$E\left[y_{i j k}\right]=E\left[\begin{array}{c}\beta_{00 i}+\beta_{1 i j} x_{i j k}+\beta_{2 i j} x_{i j k} \\ +e_{i j k}+u_{0 i j}\end{array}\right]$
$\hat{y}_{i j k}=\beta_{00 i}+\beta_{1 i j} x_{1 i j k}+\beta_{2 i j} x_{2 i j k}$

dan subtitusi estimasi parameter pada Tabel 4.2 dalam persamaan (4.9) diperoleh hasil sebagai berikut:

$\hat{y}_{j k l}=30.64+0.20 x_{1 i j k}$

$$
+0.46 x_{2 i j k}
$$

Hubungan antara level-1 dan level-2 dapat dihitung melalui nilai interclass correlation (ICC) sebagai berikut:

$$
\begin{aligned}
\rho_{12} & =\frac{\sigma_{2}^{2}}{\sigma_{2}^{2}+\sigma_{1}^{2}} \\
& =\frac{(1.23)^{2}}{(1.23)^{2}+(5.40)^{2}} \\
& =0.0493=4.93 \%
\end{aligned}
$$

Hal ini menunjukkan bahwa variasi setiap mahasiswa sangatlah kecil yakni sebesar 0.0497 atau $4.97 \%$. lebih lanjut dapat diartikan pula bahawa kemampuan siswa pada tingkat ini adalah relatif sama atau homogen. Variabilitas persamaan regresi linier pada level 2 disajikan dalam Gambar 1. Sebagi berikut: 


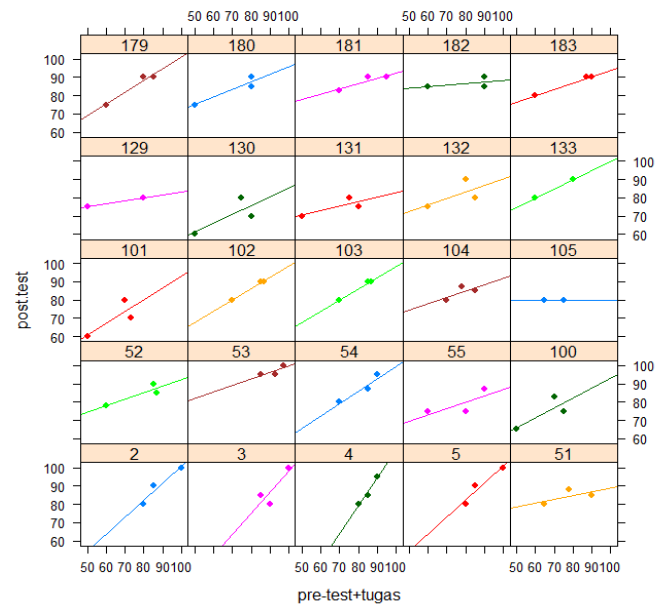

Gambar 1. Variabilitas persamaan linier pada level-2

\subsection{Analisis Pada Level-3}

Sejalan dengan analisis pada level-1 dan level-2, model untuk level 3 dapat dibangun dengan cara sebagai berikut: Misalkan diberikan model persamaan pada level-3 yakni

$$
\begin{aligned}
& \beta_{00 i}=\beta_{000}+v_{00 i} \\
& \text { dengan }
\end{aligned}
$$$$
v_{00 j} \sim N\left(0, \sigma_{v}^{2}\right)
$$

Maka diperoleh model penuh untuk level-3 dapat dituliskan sebagai berikut:

$$
\begin{aligned}
y_{i j k}= & \beta_{000}+\beta_{1 i j} x_{i j k}+\beta_{2 i j} x_{i j k}+e_{i j k} \\
& +u_{0 i j}+v_{00 i}
\end{aligned}
$$

Hasil analisis untul level-3 dijelaskan dalam Tabel 3. sebagai berikut:

Tabel 3. Hasil Analisis pada Level-3

\begin{tabular}{ccccc}
\hline Parameter & $\begin{array}{c}\text { Estimasi } \\
\text { parameter }\end{array}$ & $\begin{array}{c}\text { p- } \\
\text { value }\end{array}$ & AIC & BIC \\
\hline Cons & 30.97 & 0.00 & & \\
Pre-test & 0.20 & 0.00 & & \\
tugas & 0.46 & 0.00 & 3767.51 & 3793.95 \\
Sd level-1 & 5.27 & 0.00 & & \\
Sd level-2 & 1.01 & 0.05 & & \\
Sd level-3 & 1.31 & 0.00 & & \\
\hline
\end{tabular}

Diperhatikan persamaan ,dengan mempertimbangkan persamaan (4.2) , (4.6) , dan (4.13) maka diperoleh persamaan sebagai berikut:

$E\left[y_{j k l}\right]=E\left[\begin{array}{c}\beta_{000}+\beta_{1 i j} x_{i j k}+\beta_{2 i j} x_{i j k} \\ +v_{00 k}+u_{0 i j}+e_{i j k}\end{array}\right]$

$$
\begin{aligned}
\hat{y}_{i j k}= & 30.97+0.20 x_{1 i j k} \\
& +0.46 x_{2 i j k}
\end{aligned}
$$$$
\hat{y}_{i j k}=\beta_{000}+\beta_{1 i j} x_{i j k}+\beta_{2 i j} x_{i j k}
$$$$
\text { dan subtitusi estimasi parameter }
$$$$
\text { pada Tabel } 4.2 \text { dalam persamaan (4.15) }
$$
diperoleh hasil sebagai berikut:

Hubungan antara level-2 dan level-3 dapat dihitung melalui nilai interclass correlation (ICC) sebagai berikut:

$$
\begin{aligned}
\rho_{23} & =\frac{\sigma_{2}^{2}+\sigma_{3}^{2}}{\sigma_{1}^{2}+\sigma_{2}^{2}+\sigma_{3}^{2}} \\
& =\frac{(1.01)^{2}+(1.31)^{2}}{(5.27)^{2}+(1.01)^{2}+(1.31)^{2}} \\
& =0.0897=8.97 \%
\end{aligned}
$$

Hal ini menunjukkan bahwa variasi setiap kelas lebih tinggi daripada variasi individu yakni sebesar 0.0897 atau $8.97 \%$. Variabilitas persamaan pada level-3 disajikan dalam Gambar 2. sebagai berikut:

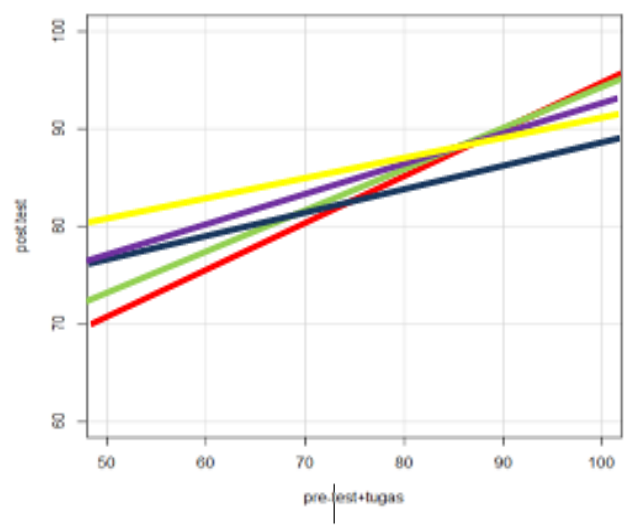

Gambar 2. Variabilitas pada level-3

\section{KESIMPULAN DAN SARAN}

Dari penelitian yang telah dilakukan dapat diambil kesimpulan sebagai berikut:

1. Diperoleh tiga buah persamaan dari setiap level yang dianalisis. 
Persamaan regresi linier terbaik diperoleh dengan cara mengambil nilai AIC atau BIC terendah untuk setiap modelnya yakni pada model penuh pada level-3 dengan persamaan sabagai berikut:

$$
\hat{y}_{j k l}=30.97+0.20 x_{1 j k l}+0.46 x_{2 j k l}
$$

2. Diperoleh korelasi antar kelas antar individu yakni pada level-2 sebesar 0.497 atau sebesar $4,93 \%$ yang dapat diartikan bahwa nilai yang diperoleh setiap mahasiswa sesungguhnya relatif identik. Selain itu diperoleh ICC antar kelas pada level-3 yakni sebesar 0,897 atau $8,97 \%$ yang menunjukkan bahwa variasi kelas lebih tinggi atau dapat dikatakan kelas lebih variatif dibandingkan dengan individu.

3. Diperoleh penurunan nilai AIC dan BIC untuk setiap level yang mengindikasikan bahwa semakin tinggi level yang digunakan maka ukuran kebaikan modelnya semakin meningkat.

Saran untuk penelitian kedepan yakni ditemukannya penurunan AIC dan BIC untuk setiap level yang mengindikasikan bahwa semakin tinggi level yang digunakan maka ukuran kebaikan model semakin meningkat, namun demikian ditemukan pula kecenderungan untuk meningkatnya nilai $p$-value di setiap levelnya yang mengindikasikan penurunan tingkat signifikansi. Untuk itu perlu dilakukan studi lanjut dengan menggunakan data yang lebih compatible dan mengandung banyak unit dalm kluster sehingga dapat diamati lebih jauh terkait kecenderungan yang ditemui.

\section{DAFTAR PUSTAKA}

Bickel, Robert., 2007. Multilevel Analysis for Applied Research. The Guildford Press. New York
Breslow, N.E. and Clayton,D.G., 1993, Aproximate Inference in GLMM, Journal of American statistical Association, 88 95-25

Goldstein, H., 2011, Multilevel Statistical Models,Jhon Wiley \& Sons,United Kingdom

Harville, D.A., 1977, Maximum Likelihood Approaches to Variance Component Estimation and to Related Problems, journal of American statistical Association, 72 320- 338

Latan, H., 2014, Aplikasi Analisis Data Statistik untuk IImu Sosial dan Sains dengan Stata, Alfabeta, Bandung

Leeden,R.V.D.,1998,Multilevel Analysis of Repeated Measure Data, Kluwer Academic Publisers, 32 15-29.

Quene H. and Berg H.V. D., 2004. On Multilevel Modeling Of Data From Repeated Measures Designs, Science Direct, 43 103-121.

Rencher,A.C. and Schaalje,G.J., 2008, Linear Model in Statistics, Jhon Wiley \& Sons, Canada

Rosadi, D.,2011, Analisis Ekometrika dan Runtun Waktu Terapan dengan $\mathrm{R}$, Andi, Yogyakarta.

Suherman, E., dkk. 2003. Strategi Pembelajaran Matematika Kontemporer. Bandung: FMIPA UPI. 